\title{
Detecting collaboration patterns among iSchools by linking scholarly communication to social networking at the macro and micro levels
}

\author{
So-Young $\mathrm{Yu}^{*}$ \\ Dept. of Library and Information Science, Hannam University, 70 Hannam-ro, Daedeok-gu, \\ Daejeon, 306-791, Korea, \\ soyoungyu201@gmail.com
}

\begin{abstract}
Information schools (iSchools) have grown along with heightened understanding of the rapid changes taking place in the information society and in the humanities. This growth has led to the characteristics of multidisciplinarity and the need for ongoing discussion and collaboration in information field (i-Field) research in terms of human behaviors and information technology. To promote collaboration in the context of research and education, it is necessary to understand the current activities of iSchools in relation to their collaboration patterns. This study analyzed the research patterns among iSchools at the macro and micro levels, and combined the analysis results
\end{abstract}

For the analysis,, 41 iSchools were identified from the iSchool directory. Co-authorship and an institution-profiling network were extracted from conference papers and posters presented at the iConference 2008-2013 to mine scholarly communication patterns. Social networks ("friendship" networks) among them were also extracted from Twitter by collecting their common followees to identify their interest in current public issues. The network analysis was performed at the micro and macro levels.

In the micro-level analysis, the structures of social networking and scholarly communication among 41 iSchools were constructed and compared statistically by executing quadratic assignment procedure (QAP) correlation. The QAP correlation analysis determines whether a relationship exists between two particular nodes in two networks at the same time. At the macro level, comparison between the top interest in social networking and that of scholarly communication was performed by revealing top co-word networks. Additionally, co-authorship patterns and institution profiling patterns among 196 institutions, including the 41 iSchools identified in scholarly communication, were compared statistically to identify similarities and differences in communication patterns of iSchools compared to non-iSchools.

The analysis provided evidence of the current prominent collaborating bodies and their neighbors as proactive actors accelerating scholarly communication and social networking. The social networking pattern and institution-profiling pattern were significantly related at the micro level, and the co-authorship pattern was significantly related to the institution-profiling pattern at macro-level. Additionally, iSchools that actively elaborate social networking and scholarly communication at the micro or macro levels were identified and compared to determine whether iSchools that could bridge other iSchools and non-iSchools in both social networking and research. The significant interest in social networking revealed in this study was related to IT trends and higher education while the research interest in the iField was related to linking information science to society, technology, and culture.

\footnotetext{
* First and Corresponding Author 
Keywords: Social network analysis, Bibliometrics, Twitter, Social networking, iSchool, iConference

\section{INTRODUCTION}

iSchools are recognized as an emerging name for information schools whose approach applies information science and technology to culture, education, and business (iSchools). Because membership and research activities of iSchools have expanded rapidly since 2003, it is important to define the major activities and research these schools have pursued to understand where they stand in the fields of research and education. Recent studies have examined the overall research activity and education programs of iSchools (Chen 2008; Subramaniam \& Jaeger 2011; Wiggins \& Sawyer 2012; Wu, He, Jiang, Dong \& Vo, 2012) and these studies could be regarded as a reflection of the need for further research.

The purpose of this study was to enhance the understanding of iSchools and their research activities by identifying their major interests in current issues and research. The researcher assumed that iSchools' social networking patterns could represent their interests in current issues, and publications could show their research interests and activities. The research questions below were based on this assumption.

RQ1. What are the major interests and concerns of iSchools in social networking?

RQ2. What are the major research topics of iSchools in scholarly communications?

RQ3. Is there a relationship between social networking and scholarly communication of iSchools at the macro and micro levels?

\section{LITERATURE REVIEW}

Quantitative and qualitative studies have analyzed research and education of iSchools to identify their research domains, educational purposes, specialties, and the characteristics and states of iSchools (Chen 2008; Subramaniam \& Jaeger 2011; Wiggins \& Sawyer 2012; Wu et al. 2012).

Chen (2008) reported the research interests and key researchers of 19 iSchools as of 2008 using the bibliographic records of 3,969 articles published between $1998-2007$ and indexed in Web of Science. This study also empirically analyzed international collaborations between iSchools and European or Japanese schools, and summed the highly cited papers using Google Scholar. Specifically, Chen attempted to use various and authoritative data sources to analyze research activity of iSchools.

Wu et al. (2012) explored research and education of 25 iSchools by analyzing 1,140 faculty members' homepages and publications obtained from the Web of Science. They analyzed iSchools' education and research productivity after categorizing 25 iSchools into three groups (Library and Information science [17 iSchools], Computer Science [4 iSchools], and Business and Management [4 iSchools]. Even though this study pointed to the lack of comprehensive analysis on iSchools as a limitation of other studies, the researcher did not provide a deep analysis for each their finding.

Comparing Chen's (2008) and Wu et al.'s (2012) research, Subramaniam and Jaeger (2011) examined the educational aspect of iSchools using 47 courses syllabi from MLIS programs at iSchools to reveal the diversity in offered courses. Additionally, Wiggins and Sawyer (2011) explored intellectual diversity in faculty composition and faculty education of 21 iSchools in the view of interdisciplinary academic environment by analyzing their websites.

Because bibliometrics and scientometrics have been major quantitative approaches in previous studies, and most analysis have focused on iSchools, the data collected and analyzed have been from iSchools' researchers and faculties. This approach could provide a compact and overall view on the current state of iSchools; however, it could also pass over LIBRES ISSN 1058-6768 Volume 23, Issue 2, September 2013 
the structural context of iSchools with so-called non-iSchools. Another key feature of related studies is the insufficient evidence linking iSchools' interests in current issues and pertinent research output. Therefore, describing the state and identity of iSchools in terms of their missions and origins could provide valuable insight. Therefore, this study, included institutions that participated in social networking and scholarly communication with iSchools.

\section{METHODOLOGY}

This study was executed using the following four steps (see Figure 1): data collection, preprocessing and network extraction, micro-level analysis with 41 iSchools, and macro-level analysis with 196 iSchools and non-iSchools.

\subsection{Research Design}

Data collection was executed to collect two different dataset, Twitter data and research papers. Preprocessing was performed to extract networks analyzed; this step aimed to unify institution name variants and index authors' keywords in the research papers.

The researcher conducted two different levels of analysis and one unit of all analysis was used for individual universities that had one or more iSchools. For example, Indiana University, which had two iSchools (the School of Informatics and Computing and the School of Library and Information Science) under the iSchool Directory as of April 2013 was treated as one iSchool for Indiana University. Micro-level analysis was executed by visualizing three different networks of 41 iSchools and statistically testing correlations between them. Macrolevel analysis was performed by visualizing research activities among 196 iSchools and noniSchools and testing the correlations between co-authoring networks and institution profiling networks. The networks analyzed were denoted under the micro and macro-level analyses (see Figure 1).

The list of 41 iSchools was retrieved and collected from the official iSchool Directory (http://iSchools.org/directory/) as of April 2013 (see Table 2), and their official Twitter accounts were identified from each school's official Web sites. As shown in Table 2, only 40 iSchool names were listed because Indiana University had two iSchools, as denoted with an asterisk.

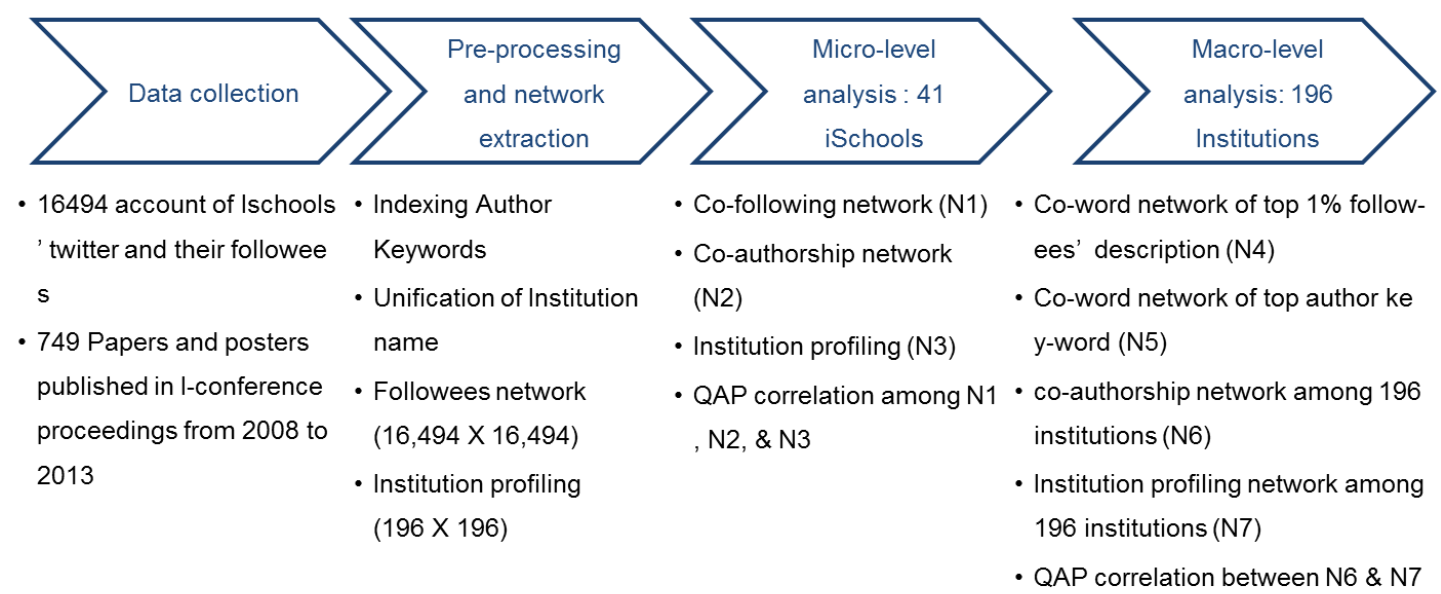

Figure 1. Research design 


\subsection{Data Collection}

For social networking, the iSchools' Twitter accounts and their followees, with their links, were collected using NodeXL v.1.28 (Hansen, Shneiderman, \& Smith 2010). NodeXL is an open-source template that is widely used in research to analyze Twitter and other SNS data and visualize these networks. After checking all 41 iSchools' official websites, 9 iSchool did not provide Twitter account on their official websites, and the two iSchools from Indiana University used the same Twitter account. Therefore, the 31 Twitter accounts of iSchools were used for crawling (i.e., collecting the iSchools' following and being followed relationships in Twitter). The crawling was performed on June 17, 2013. The total number of unique accounts identified was 16,494 , and 25 iSchools were found to be following each other on Twitter.

For scholarly communications, all 749 papers and posters published in the iConference proceedings from 2008 to 2013 were selected and collected from the official proceedings to identify scholarly communications among the 41 iSchools and non-iSchool institutions. All proceedings, except 2011 and 2012, were collected from the IDEALS Website (https://www.ideals.illinois.edu/handle/2142/14872 ); the proceedings from 2011 and 2012 were collected from the ACM Digital Library Website (http://dl.acm.org/event.cfm?id=RE615\&CFID=233110227\&CFTOKEN=50918548 ).

The collected bibliographic fields included title, author keywords, author full name, institution name, department name, email address, and additional subject category when presented. The unique 196 institutional names were identified, and 31 of 41 iSchools were found to have published more than one paper or poster in the iConference proceedings. The number of articles (papers and posters) published in each year is shown in Table 1. The data in Table 2 shows the list of 40 iSchools and countable characteristics including the number of followees/followers/tweets/favorites and published papers.

Table 1. The number of articles published in dataset

\begin{tabular}{|l|l|l|l|r|r|l|l|}
\hline & \multicolumn{1}{|l|}{ '08 } & \multicolumn{1}{l|}{ '09 } & \multicolumn{1}{l|}{10} & \multicolumn{1}{l|}{11} & \multicolumn{1}{l|}{12} & \multicolumn{1}{l|}{ Total } \\
\hline No. of article & 62 & 107 & 130 & 175 & 148 & 127 & 749 \\
\hline
\end{tabular}

Table 2. Measures in the dataset of iSchools

\begin{tabular}{|c|c|c|c|c|c|c|}
\hline iSchool (University Name) & Notion & \begin{tabular}{|l|} 
Follow- \\
ees
\end{tabular} & $\begin{array}{l}\text { Follow- } \\
\text { ers }\end{array}$ & Tweets & $\begin{array}{l}\text { Favor- } \\
\text { ites }\end{array}$ & Papers \\
\hline Carnegie Mellon University & carnegie mellon university & 996 & 3,200 & 3583 & 586 & 5 \\
\hline Drexel University & drexel university & 1,057 & 955 & 894 & 11 & 33 \\
\hline Florida State University & florida state university & 149 & 630 & 263 & 0 & 34 \\
\hline Georgia Institute of Technology & georgia institute of technology & 2,899 & 3,591 & 1,696 & 38 & 5 \\
\hline Humboldt-Universitat zu Berlin & universitat zu berlin & 34 & 2,771 & 175 & 0 & 1 \\
\hline Indiana University (SolC)* & \multirow{2}{*}{ indiana university } & \multirow{2}{*}{383} & \multirow{2}{*}{1,297} & \multirow{2}{*}{2,480} & \multirow{2}{*}{20} & \multirow{2}{*}{30} \\
\hline Indiana University (SLIS)* & & & & & & \\
\hline Nanjing University & nanjing university & 0 & 0 & 0 & 0 & 2 \\
\hline Northumbria University & northumbriauni & 318 & 11,416 & 2,143 & 277 & 0 \\
\hline NOVA University of Lisbon & NOVA University of Lisbon & 0 & 0 & 0 & 0 & 0 \\
\hline $\begin{array}{l}\text { Royal School of Library and } \\
\text { Information Science }\end{array}$ & $\begin{array}{l}\text { royal school of library and } \\
\text { information science }\end{array}$ & 0 & 0 & 0 & 0 & 3 \\
\hline $\begin{array}{l}\text { Rutgers, The State University of } \\
\text { New Jersey }\end{array}$ & rutgers university & 188 & 1,585 & 1,220 & 10 & 22 \\
\hline Singapore Management University & sgsmu & 12 & 1,257 & 725 & 0 & 0 \\
\hline Syracuse University & syracuse university & 1,308 & 5,916 & 14,197 & 207 & 88 \\
\hline Pennsylvania State University & pennsylvania state university & 2,008 & 2,083 & 1,470 & 29 & 29 \\
\hline Tsukuba University & university of tsukuba & 0 & 0 & 0 & 0 & 2 \\
\hline University College Dublin & university college Dublin & 0 & 0 & 0 & 0 & 2 \\
\hline University College London & melissaterras & 1,231 & 4,597 & 15,225 & 1 & 0 \\
\hline University of Amsterdam & uva_amsterdam & 191 & 6,703 & 1,223 & 0 & 0 \\
\hline University of British Columbia & university of british columbia & 617 & 184 & 108 & 4 & 19 \\
\hline University of California, Berkeley & ucberkeley & 268 & 1,354 & 915 & 78 & 13 \\
\hline
\end{tabular}




\begin{tabular}{|c|c|c|c|c|c|c|}
\hline iSchool (University Name) & Notion & $\begin{array}{r}\begin{array}{r}\text { Follow- } \\
\text { ees }\end{array} \\
\end{array}$ & $\begin{array}{r}\text { Follow- } \\
\text { ers }\end{array}$ & Tweets & $\begin{array}{r}\begin{array}{r}\text { Favor- } \\
\text { ites }\end{array} \\
\end{array}$ & Papers \\
\hline University of California, Irvine & ucirvine & 104 & 495 & 901 & 9 & 14 \\
\hline $\begin{array}{l}\text { University of California, Los } \\
\text { Angeles }\end{array}$ & ucla & 0 & 0 & 0 & 0 & 24 \\
\hline University of Glasgow & University of Glasgow & 0 & 0 & 0 & 0 & 0 \\
\hline University of Illinois & $\begin{array}{l}\text { University of Illinois at Urbana- } \\
\text { Champaign }\end{array}$ & 335 & 1,778 & 2,609 & 40 & 45 \\
\hline University of Kentucky & university of Kentucky & 137 & 440 & 459 & 4 & 4 \\
\hline University of Maryland & university of maryland & 841 & 764 & 1,177 & 1 & 31 \\
\hline $\begin{array}{l}\text { University of Maryland, Baltimore } \\
\text { County }\end{array}$ & umbc & 76 & 61 & 169 & 0 & 1 \\
\hline University of Melbourne & unimelb & 822 & 22,750 & 5,007 & 443 & 0 \\
\hline University of Michigan & university of michigan & 629 & 1,936 & 2,932 & 105 & 29 \\
\hline University of North Carolina & $\begin{array}{l}\text { university of north carolina at } \\
\text { chapel hill }\end{array}$ & 129 & 996 & 1,026 & 12 & 22 \\
\hline University of North Texas & university of north texas & 161 & 300 & 361 & 2 & 28 \\
\hline University of Pittsburgh & university of pittsburgh & 83 & 149 & 118 & 0 & 33 \\
\hline University of Sheffield & university of sheffield & 11 & 321 & 226 & 0 & 1 \\
\hline University of South Australia & universitysa & 1,666 & 9,609 & 3,514 & 211 & 0 \\
\hline University of Tampere & University of Tampere & 0 & 0 & 0 & 0 & 0 \\
\hline University of Texas, Austin & university of texas at austin & 725 & 942 & 527 & 14 & 16 \\
\hline University of Toronto & university of toronto & 120 & 2,005 & 443 & 3 & 26 \\
\hline University of Washington & university of washington & 282 & 483 & 609 & 35 & 48 \\
\hline University of Wisconsin, Milwaukee & $\begin{array}{l}\text { university of wisconsin- } \\
\text { milwaukee }\end{array}$ & 54 & 443 & 396 & 0 & 13 \\
\hline Wuhan University & wuhan university & 0 & 0 & 0 & 0 & 8 \\
\hline
\end{tabular}

\subsection{Preprocessing and Network Extraction}

Unifying the institution's name was performed manually, and indexing author keywords was executed using Natural Language Toolkit (NLTK) 2.0 (Bird, Klein, \& Loper 2009). Natural Language Toolkit is an open-source module coded in Python for natural language processing and text analysis. The indexing yielded 1,520 unique terms from the author keywords fields; no stemming process was executed. Index terms were extracted using Tokenizer modules of NTLK. For network extraction, the co-following and co-authorship networks were calculated using co-occurrence of following or authoring.

Institutional profiling was also performed, which is helpful in identifying invisible colleges. Institution profiling is a method of constructing a similarity network among institutions using co-occurring keywords. The profiling was extracted by manipulating (Institution X Article) the matrix and (Keyword $X$ Article) $T$ matrix. After matrix manipulation, a cosine similarity measure was used to calculate the similarity between two institutions. This method is similar to 'Author Profile Vector' (Kim \& Lee, 2007).

Assume that there are two institutions, A and B. Institution A publishes Doc1 while Institution B publishes Doc2 as represented in the Authorship matrix (see Figure 2). Given that both of Doc1 and Doc 2 have the same Keyword1 in the Keyword Occurrence matrix, we can find that A shares the same keyword with B in the Institution-Keyword matrix; therefore, they are linked by the same keyword in the Institution Profiling Matrix. Thus, we can infer that $A$ and $B$ are in the same invisible college as they share the same research interests. That is, the institution profiling method can detect invisible colleges in terms of research interests represented by shared keywords regardless of direct co-authoring. 


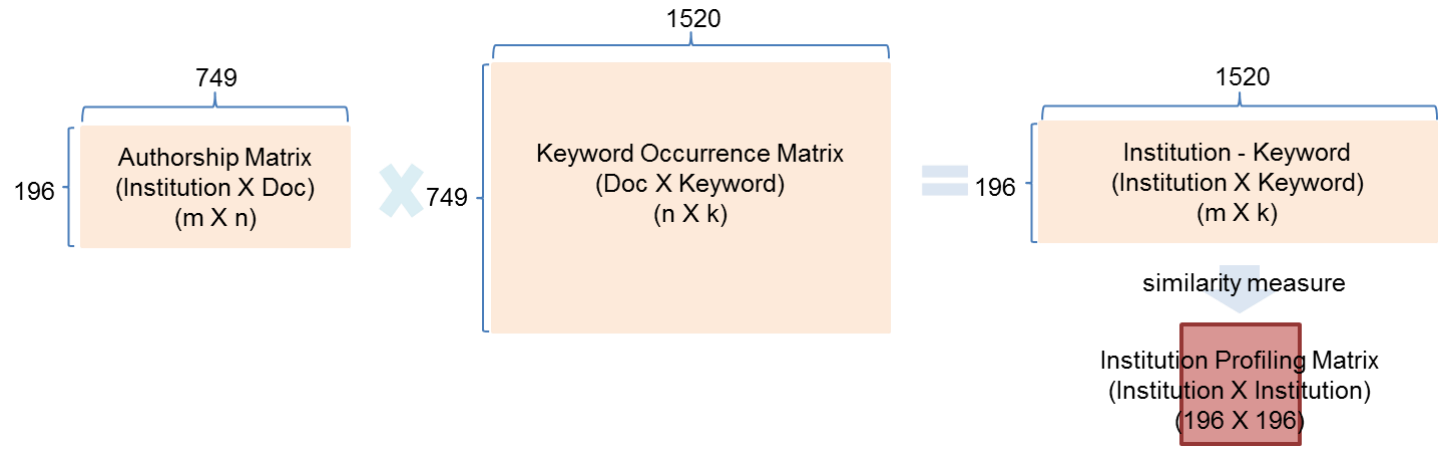

Figure 2. Institution Profiling Method

\subsection{Micro-level and Macro-level Analyses}

The meaning of macro or micro level was operationally defined in this study. Macro-level analysis includes all institutions present in the social networking or research activity along with the 41 iSchools to see communications between iSchools and non-iSchools. Micro-level analysis included only the 41 iSchools to see inter-iSchool communications. The networks analyzed matched the pertinent level of analysis and the research questions (see Table 3).

Table 3. Research questions and corresponding networks at respective level of analysis

\begin{tabular}{|l|l|l|l|}
\hline \multicolumn{1}{|c|}{ Level of Analysis } & \multicolumn{1}{|c|}{ RQ1 } & RQ2 & \multicolumn{1}{c|}{ RQ3 } \\
\hline Micro-level analysis & N1 & N2 \& N3 & QAP correlation among N1,2,\&3 \\
\hline Macro-level analysis & N4 \& N5 & N6 \& N7 & $\begin{array}{l}\text { Comparison between N4 \& N5 } \\
\text { QAP correlation between N6 \& N7 }\end{array}$ \\
\hline
\end{tabular}

To identify the structural associations among networks, a quadratic assignment procedure (QAP) correlation was performed. A QAP is a useful way to verify the relation between two different networks of the same nodes by comparing the networks directly (Hanneman \& Riddle 2005). A QAP-correlation analysis examines whether an association between two nodes in a network is significantly related to the association between the same nodes in another network to determine whether a relationship exists between two particular nodes in two networks at the same time (Hanneman \& Riddle 2005). To visualize the core structure of the networks, a Pathfinder algorithm (Quirin, Cordón, Guerrero-Bote, VargasQuesada \& Moya-Anegón, 2008; Schvaneveldt, 1990) was applied. Pathfinder network is widely used in network visualization to extract the backbone structure of a dense network. The QAP-correlation was performed using UCINET 6 (Borgatti, Everett Freeman, 2002), and NetworkWorkbench (NWBTeam, 2006) was used to extract PathFinder networks. Visualizing these networks and calculating centrality measures were executed by using Pajek (Nooy, Mrvar \& Batagelj, 2011).

\section{RESULTS : RELATIONSHIP BETWEEN SOCIAL NETWORKING AND SCHOLARLY COMMUNICATIONS}

The researcher performed a micro-level analysis to determine the linkage between social networking and scholarly communication among iSchools. At the macro level, comparison between the top interests in social networking and that of scholarly communication was 
performed. Two different scholarly communication patterns among the 196 iSchools and noniSchools were compared statistically to determine similarities and differences.

\subsection{Social Networking and Scholarly Communication at Micro-Level}

At the micro level, co-following networks on Twitter, collaboration, and the institution profiling networks among the 41 iSchools were analyzed to mine similar activity patterns on the networks.

\subsubsection{Social Networking and Research Activity}

Two major components were identified in the social networking activity at the micro level: one was a Syracuse University-centered group and the other was a University of Marylandcentered group. The latter had the following three sub-components: The Georgia Institute of Tech-centered, the University of British Columbia-centered, and the Drexel Universitycentered, clockwise.

The candidates identified for the bridging role in social networking were Syracuse University (0.033) and Drexel University (0.037), which had high values of betweenness centrality denoted as the size of the node in the map in Figure 3 . These were followed by Indiana University (0.023), the University of Maryland (0.015), and the University of British Columbia (0.015).

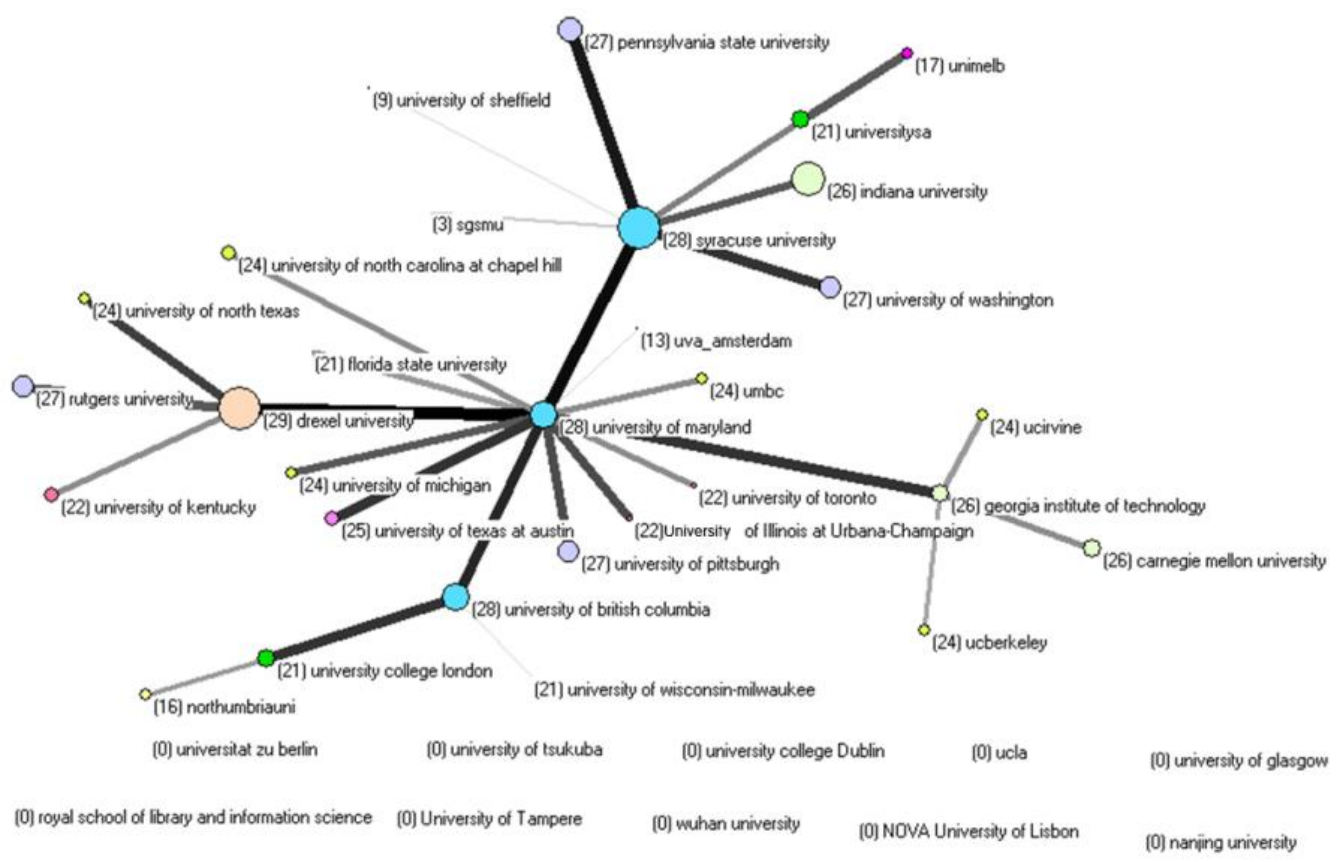

Figure 3. Pathfinder Network of Co-following among 41 iSchools (PF-N1, size of node = betweeness centrality in $\mathrm{N} 1$, the number in parenthesis = degree centrality in N1)

Compared to social networking, co-authoring between the 41 iSchools was relatively sparse, and the number of co-authoring papers (denoted as link width in Figure 3) was very small. The maximum number of co-authored papers was five, which was the value between the University of Pittsburgh and Wuhan University. The University of Michigan seemed actively involved in co-authorship with eight iSchools, followed by the University of Pittsburgh (six) and the University of Washington (five). Seventeen iSchools (43\% of 41 iSchools) had no collaboration. In the co-authoring network, the University of Michigan (0.228) was identified as the most prominent candidate for a brokerage role because of its high value of LIBRES ISSN 1058-6768 Volume 23, Issue 2, September 2013 
betweenness centrality, denoted as the size of the node in the map of Figure 4. This school was followed by the University of Washington (0.183) and the University of Pittsburgh (0.162).

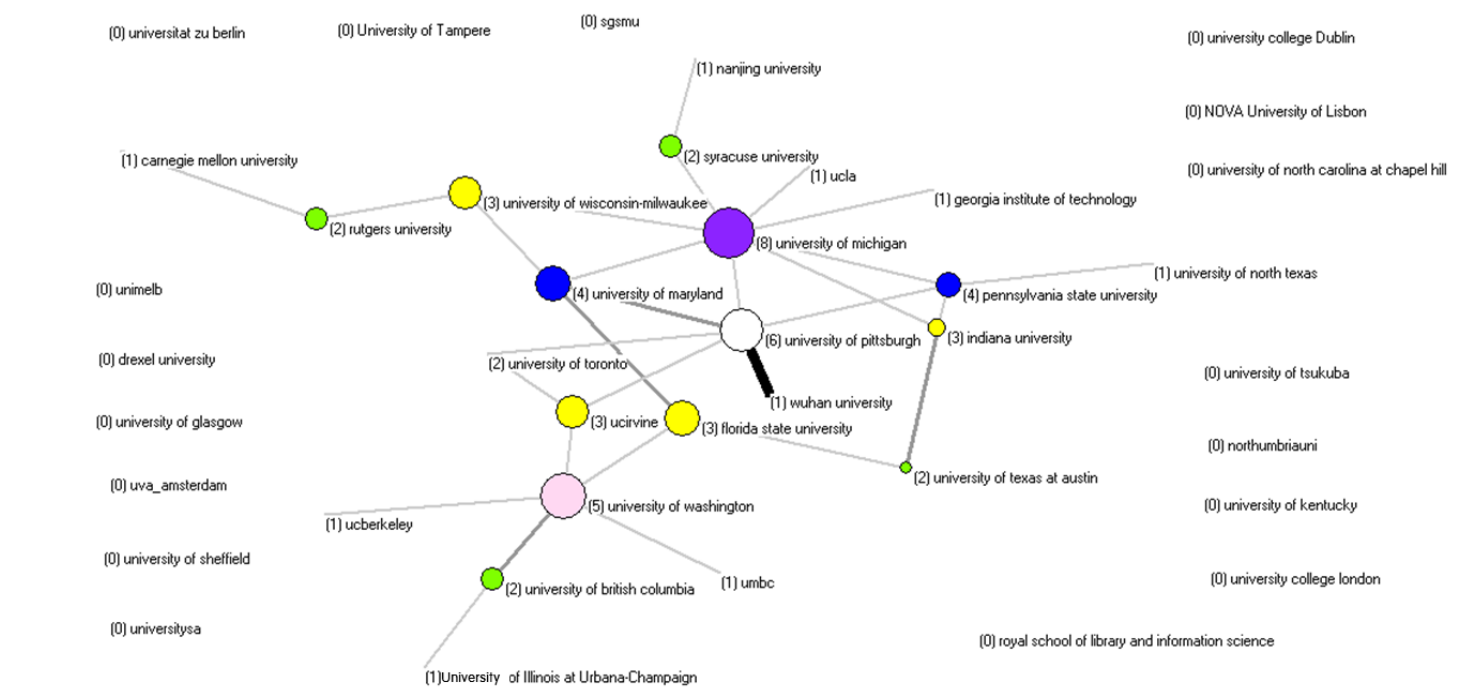

Figure 4. Collaboration Network of 41 iSchools (N2, size of node = betweeness centrality in N2, the number in parenthesis $=$ degree centrality in N2)

In addition to the co-authorship network, an institution-profiling network could show indirect collaboration by sharing common research interests. Four components were revealed in the institution-profiling network: Component 1, located in the upper left, consists of Syracuse University and its connected neighbors and Component 2, in the center of Figure 4, is Florida State University-centered. Component 3, at the lower right in the same map, includes the University of Illinois at Urbana-Champaign and its neighbor. Finally, Component 4 consists of isolated schools around the network. The University of Florida played a bridging role in the network by locating itself between the components for the University of Illinois at Urbana-Champaign and Syracuse University. The number of brokers in the institution-profiling network was relatively larger than that in the previous two networks only regarding the value of betweenness centrality. In terms of the structural position and betweenness centrality, Syracuse University (0.005) and the University of Illinois at Urbana-Champaign (0.005) could be the most reasonable candidates for the role. Additionally, the University of Pittsburgh could be considered in terms of efficiency of collaboration because of its consistent connection with Wuhan University in both N2 and N3. Even though the University of Pittsburgh in N3 (Figure 5 ) is not located on the main stream, but linked to Syracuse University in Component 3, it is still linked to Wuhan University. 


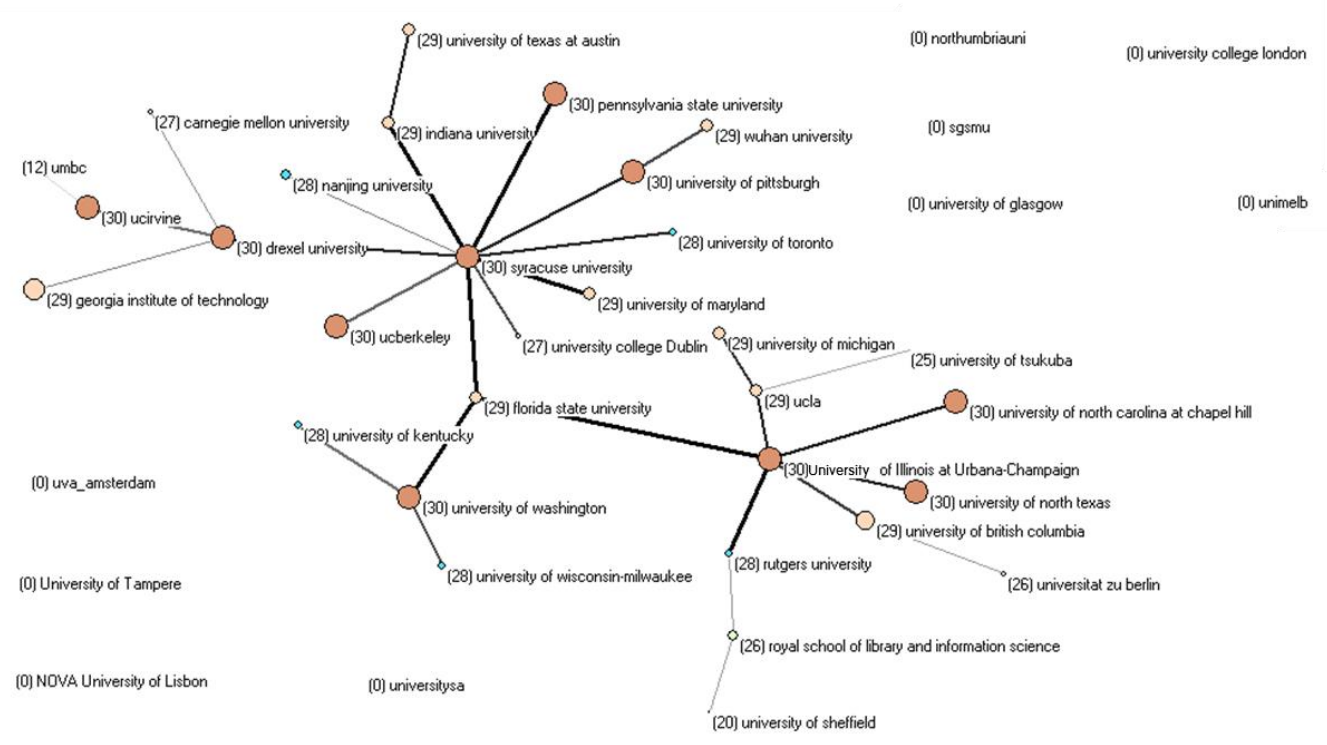

Figure 5. Pathfinder Network of institution profiling among 41 iSchools (PF-N3, size of node = betweenness centrality in N3, the number in parenthesis = degree centrality in N3)

\subsubsection{Comparison between Social Networking and Scholarly Communication}

The results show that the social networking pattern among iSchools was related to their scholarly communication patterns, even though they rarely co-worked with each other (see Table 4). When comparing the linking structures among three networks directly using a QAPcorrelation, the pattern of expressing social interest among iSchools was moderately related to that of the research interest among them $(r=.41, p<.01)$. However, the pattern of publishing papers with their research interest was not significantly related to that of collaboration on the papers $(r=.24, p>.01)$. This finding implies that iSchools' common interests in networking are related to their common research topics in papers published in the iConference proceedings; however, the linkage between interest in current issues and collaboration in research was not significant.

Table 4. QAP-correlation at micro-level analysis

\begin{tabular}{|l|r|r|r|}
\hline & N1 & N2 & N3 \\
\hline N1 & 1.00 & & \\
\hline N2 & $0.06^{* *}$ & 1.00 & 1.00 \\
\hline N3 & $0.41^{* *}$ & 0.24 & ${ }^{* *} p<.01$ \\
\hline
\end{tabular}

\subsection{Social Networking and Scholarly Communication at Macro-Level}

At the macro level, iSchools' major interests in social network and scholarly communication were analyzed. The direct collaboration patterns among iSchools and noniSchools were compared visually and statistically with institution profiling to determine similarities between them.

\subsubsection{Major Interest in Current Issue and Research}

The maps shown in Figure 6 provide major interest that drives social networking and scholarly communications between iSchools and non-iSchools. PF-N4 represents top interests as described by more than two of the top $1 \%$ of followees (166 followees) at the LIBRES ISSN 1058-6768 Volume 23, Issue 2, September 2013 
same time. The top topics were divided into two components: Trends in IT and IT business on the left and higher education on the right of the map. The terms 'computing' (11), 'digital' (9), 'editor' (11), or 'college' (7) were revealed as having many co-occurring keywords and played brokerage roles in $\mathrm{N} 4$.

Compared to PF-N4, PF-N5 shows the top research interests, which co-occurred in more than five documents of the dataset. The most frequently co-occurring keyword was 'information.' This key word was excluded in PF-N5 because its dominant co-occurrence included co-occurring keywords of 'information' within other prominent keywords. As a result, PF-N5 (Figure 6) shows 92 prominent keywords and their major co-occurrence, which reveals the top research interests in iResearch. The major research topics found including information behavior in social networks and Web 2.0, such as social tagging and collaborative filtering, which is located at the center of PF-N5. In addition to this interest, issues in digitalization (top right), $\mathrm{HCl}$ (bottom left), and cultural and demographical approaches (bottom right) were identified as top research interests.
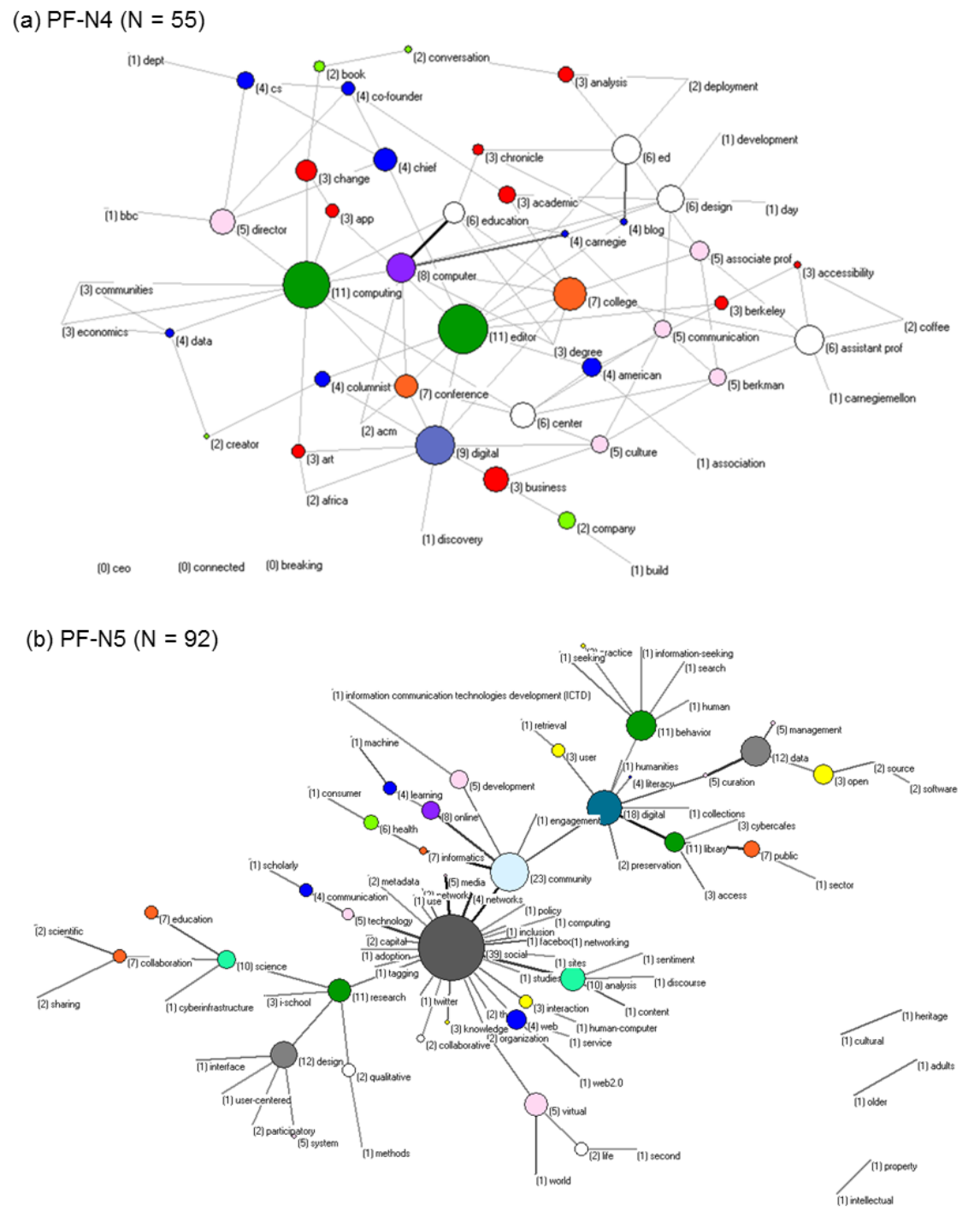

Figure 6. Pathfinder Network of top interest in social networking and research (size of node $=$ betweenness centrality, the number in parenthesis = degree centrality) 


\subsubsection{Comparison of Two Scholarly Communication Patterns among iSchools and Non-iSchools}

Comparison of the core structure of scholarly communication in collaboration and institution profiling is shown in Figure 7. Both parts (a) and (b) show that only a few iSchools establish a scholarly communication channel with non-iSchools. Additionally, most of the 41 iSchools (red nodes) were located on the backbone of PF-N7 while few iSchools were on the backbone of PF-N6. This finding was statistically supported by the QAP-correlation between $\mathrm{N} 6$ and N7. The collaboration patterns of iSchools with other institutions was moderately similar to the institution profiling revealed in the QAP-correlation analysis $(r=.39, p<.01)$.

The iSchools within the backbone of each network were differentiated. The University of Washington, University of Michigan, University of Maryland, and University of WisconsinMilwaukee were located on the backbone of PF-N6 while the University of Illinois at UrbanaChampaign, Florida State University, and Syracuse University were on the backbone of PFN7.

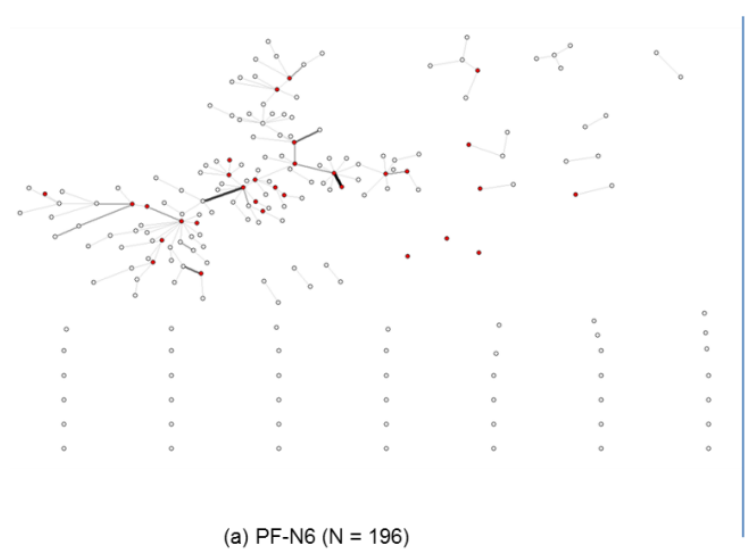

Figure 7. Scholarly communication Patterns

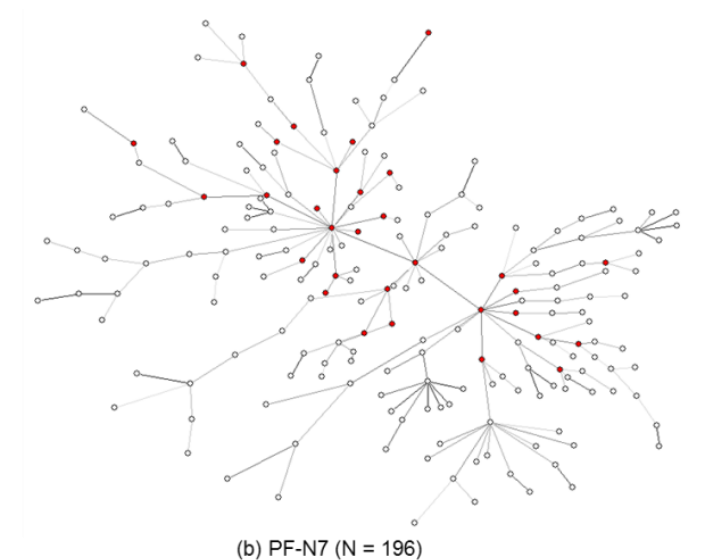

((a) Coauthorship (b) Institution Profiling)

\section{DISCUSSION}

This study identified inter-iSchools' collaboration patterns by analyzing their social networking and scholarly communications and investigating their connections to non-iSchools and other bodies. Compared to Chen's (2008) analysis, this study provided more networkstructural and statistically significant result using the QAP. In addition, by comparing Twitter data with iConference data, this study examined a link between social networking and scholarly communications empirically, which previous studies have rarely analyzed. Other studies have tended to focus on analyzing scholarly communications, education programs, or funding programs that primarily relate to research and education, even though few studies have attempted to determine other aspects of iSchools such as careers of iSchool graduates (Rathbun-Grubb, 2009; Marshall, Morgan \& Marshall, 2009) or online doctoral student communities (Naughton, Hall, Zhao \& Lin, 2010). Wu et al. (2012) have noted these gaps in the literature; however, even their study focused only on the similar aspects (i.e., research, education, and career) using different datasets.

Based on the current results, the prominent actors at the micro or macro levels could be interpreted in terms of collaboration and research domains. In terms of direct collaboration in research, the University of Washington and University of Michigan were found to be the most active iSchools at both the micro and macro levels. In terms of research topics, Syracuse University and the University of Illinois at Urbana-Champaign were revealed as the most prominent actors in sharing various research topics in common at both levels. The University of Maryland and University of Wisconsin-Milwaukee were identified as active collaborators at the macro level, and the University of Pittsburgh was recognized as the same at the micro 
level. An interesting finding was that Drexel University, an iSchool revealed as an actor that actively elaborates social networking and scholarly communications, was significantly inactive in scholarly collaboration.

This study also found that iSchools' major interests in current issues were relatively practical because their interests in tracking current trends in IT and higher education, which can be a base for maintaining iSchools and iResearch. Social networking patterns were significantly related to common research interests; however, these research interests and research activities were not highly correlated to each other in the iResearch domains.

The results of this study are limited by the dynamic nature of the iSchool community. Several new iSchools have become members of the iSchools organization since the data were collected in June 2013. Therefore, the analysis in this study represents a snapshot of 41 iSchools, which evokes follow-up research that includes these new members. As a follow-up, further studies are needed to investigate the prominent structural actors and their connections in social networking and scholarly communication dynamically with department- or researcher-level analysis from various datasets.

\section{CONCLUSION}

Because the findings in this study were from direct or indirect relationships, such as social networking or co-authoring, they can be regarded as relational characteristics of iSchools. The linkage between iSchools' social networking and scholarly communications found in this study could be empirical evidence of finding proactive iSchools with other iSchools or non-iSchools in either or both of these activities. From the results and discussions, it is also inferred that few 'hub' iSchools exist that could link iSchools and non-iSchools by collaborating or sharing common research interests. In addition to the fact that the iSchool community is currently expanding its research field and educational potent, there has been many endeavors to enhance the understanding the iSchools. Thus, this study can be regarded as an exploratory approach to reveal relational characteristics of iSchools and enrich understanding.

\section{REFERENCES}

Bird, S., Klein, E., \& Loper, E. (2009). Natural Language Processing with Python. Sebastopol, CA, USA:O'Reilly Media.

Borgatti, S.P., Everett, M.G. \& Freeman, L.C. (2002). Ucinet for Windows: Software for Social Network Analysis. Harvard, MA: Analytic Technologies.

Chen, C. (2008). Thematic maps of 19 iSchools. In: Proceedings of the American Society for Information Science and Technology Conference, 2008, 24-29 October, Ohio, USA. New York: ASIS\&T, 2008, pp. 1-12.

Freeman, L. C. (1978). Centrality in social networks conceptual clarification. Social Networks, 1 (3), 215-239.

Hanneman, R. A., \& Riddle, M. (2005). Introduction to social network methods. Retrieved from http://faculty.ucr.edu/ hanneman/

Hansen, D., Shneiderman, B., \& Smith, M. A. (2010). Analyzing social media networks with NodeXL: Insights from a connected world. Amsterdam: Morgan Kaufmann.

iSchools. Retrieved from http://iSchools.org/directory/

iSchool Directory. Retrieved from http://iSchools.org/directory/

Karunakaran A., Kim H.W., Khabsa M. (2009). iSchools and social identity - a social network analysis. In: Proceedings of iConference 2009, 8-11 February, North Carolina, USA. Retrieved from http://www.personal.psu.edu/hxk263/docs/SNA iSymposium2009.pdf 
Kim, P.J. \& Lee, J.Y. (2007). Descriptor profiling for research domain analysis. Journal of the Korean Society for Information Management, 24 (4), 285-303.

Marshall J.G., Morgan J.C., Marshall V.W. (2009). Workforce issues in library and information science 2 (WILIS 2): implementing a model for career tracking of lis graduates. In: Proceedings of iConference 2009, 8-11 February, North Carolina, USA. Retrieved from https://www.ideals.illinois.edu/bitstream/handle/2142/15328/WILIS-2 poster iSchools.pdf?sequence $=3$

Naughton R., Hall C., Zhao H., \& Lin X. (2010). PhD portal: developing an online iSchool doctoral student community. In: Proceedings of iConference 2010, 3-6 February, Illinois, USA. Illinois: University of Illinois at Urbana Champaign, 2010, pp. 500-502.

NLTK 2.0. Retrieved from http://nltk.org/

NodeXL. Retrieved from http://nodexl.codeplex.com/

Nooy, W. D., Mrvar, A., \& Batagelj, V. (2011). Exploratory Social Network Analysis with Pajek $\left(2^{\text {nd }}\right.$. Ed. $)$ Cambridge, UK: Cambridge University Press.

NWBTeam. (2006). Network Workbench Tool. Indiana University, Northeastern University, and University of Michigan. Retrieved from http://nwb.slis.indiana.edu

Quirin, A., Cordón, O., Guerrero-Bote, V. P., Vargas-Quesada, B., \& Moya-Anegón, F. (2008). A Quick MST-based Algorithm to Obtain Pathfinder Networks. Journal of the American Society for Information Science and Technology, 59 (12), 1912-1924. doi:10.1002/asi.20904

Rathbun-Grubb S.(2009). What happens to iSchool graduates? using career data to support ischool engagement initiatives. In: Proceedings of iConference 2009, 8-11 February, North Carolina, USA. Retrieved from https://www.ideals.illinois.edu/bitstream/handle/2142/15329/RathbunGrubb_iSchools.pdf?sequence=3

Schvaneveldt, R. W. (Ed.) (1990). Pathfinder Associative Networks: Studies in Knowledge Organization. Norwood, NJ: Ablex.

Subramaniam, M.M., \& Jaeger, P.T. (2010). Weaving diversity into LIS: An examination of diversity course offerings in iSchool programs. Education for Information, 28 (1),1-19.

Wiggins, A. \& Sawyer, S. (2012). Intellectual diversity and the faculty composition of iSchools. Journal of the American Society for Information Science and Technology, 63 (1), 821.

Wu, D., He, D., Jiang, J., Dong, W., \& Vo, K. (2012). The state of iSchools: an analysis of academic research and graduate education. Journal of Information Science, 38 (1), $15,-36$. 